\title{
Novas evidências linguísticas (e algumas arqueológicas) que apontam para a origem dos povos tupi-guarani no leste amazônico*
}

\author{
Antônio Augusto Souza Mello** \\ Andreas Kneip ${ }^{* * *}$
}

\begin{abstract}
Resumen
La forma más común de búsqueda de evidencias acerca de la ubicación geográfica de una proto-lengua se llama “Teoría de la Migración Lingüística". La región de mayor diversidad dentro de la familia es la más probable como zona original habitada por un proto-pueblo. El diálogo con otras ciencias afines, como la arqueología, la etnohistoria y la cultura comparada, es esencial para una mejor composición del pasado. En la actualidad hay cuatro hipótesis acerca del origen y la dispersión de los pueblos de la familia Tupi-Guaraní: tres a base de datos lingüísticos y una basada en datos arqueológicos. Las hipótesis lingüísticas postulam para la familia Tupi-Guarani el mismo territorio original que para el tronco Tupi. Buscamos demostrar que la zona de mayor diversidad Tupi-Guaraní no coincide con la del tronco Tupi. Esta diversidad puede ser comprobada mediante parámetros fonológicos e isoglosas léxicas que permiten delimitar algunos subgrupos lingüísticos.
\end{abstract}

Palabras clave: Tupi-Guaraní, origen y dispersión, Teoría de la Migración Lingüística.

\section{New linguistic (and some archeological) evidence that point the origin of the tupi-guarani peoples in eastern amazon}

\begin{abstract}
The most common procedure to search for evidence about the geographical location of a proto-people is called "Linguistic Migration Theory". The area that concentrates the greatest linguistic diversity within the family is the most likely to be the origin of the proto-population. The dialogue with another sciences (archeology, etnohistory and comparative culture) is fundamental for a better composition of the past. There are four major hypothesis for the Tupi-Guarani family origin and dispersion, three based on linguistic data and one based on archaeological evidence. The linguistic hypothesis supposes that the origin of the TupiGuarani family in a similar place of the Tupi stock. We shall demonstrate here that the area of highest Tupi-Guarani family diversity of the family does is not the same of the Tupi stock. This diversity can be proved with pholological parameters and lexical isoglosses that delimitate some linguistic subgroups.
\end{abstract}

Keywords: Tupi-Guarani, origin and dispersion, Linguistic Migration Theory.

\footnotetext{
* Comunicação apresentada no Coloquio de Lingüística Histórica, na Pontificia Universidad Católica de Chile, Santiago de Chile, 13 e 14 de outubro de 2015.

** Brasileiro. Doutor em Linguística. Docente no Departamento de Linguística, Português e Línguas Clássicas e do Programa de Pós-Graduação em Linguística da UnB, Universidade de Brasília. Brasília/ DF, Brasil. augmello@unb.br

**** Brasileiro. Doutor em Arqueologia. Docente no Curso de Ciência da Computação e no Programa de Pós-Graduação em Modelagem de Sistemas. Universidade Federal do Tocantins. Palmas/TO, Brasil. andreas@uft.edu.br
} 


\section{Introdução}

O volume de dados linguísticos oriundos de fontes primárias vem crescendo nas últimas décadas, o que nos permite avançar os estudos comparativos e as hipóteses de origem e dispersão de famílias linguísticas associadas a estes estudos. As línguas do tronco Tupi e da família TupiGuarani têm sido razoavelmente estudadas, o que possibilita a aplicação das hipóteses "Age Area" (Crowley, 1997) e "Linguistic Migration Theory" (Campbell, 1999) com maior precisão. Esta teoria focaliza a classificação interna (subagrupamentos) da família linguística e a distribuição geográfica das línguas, e baseia-se num modelo de diversidade máxima e movimento mínimo. As ramificações mais altas das árvores de classificação das línguas (as primeiras divisões da família) refletem uma maior profundidade temporal. A localização dos subgrupos de divisões mais antigas e a distribuição geográfica apontarão para a área de origem de um proto-povo (chamado por Sapir de centro de gravidade (Campbell, 1999)).

Este trabalho é um desdobramento do modelo apresentado no XIII Congresso da Sociedade Brasileira de Arqueologia (Mello e Kneip, 2005), que propõe uma alteração na hipótese da origem e dispersão dos povos Tupi-Guarani. Apresentaremos aqui as evidências linguísticas que permitem propor esta alteração, que considera o leste amazônico como mais provável área de origem Tupi-Guarani. Propondo esta origem, o traçado das possíveis migrações tem de ser refeito, inclusive as referentes aos povos que deram origem aos Tupinambá.

Primeiramente apresentaremos um pequeno resumo das hipóteses linguísticas de Urban $(1992,1996)$ e Rodrigues (2000), que coincidem em grande parte, e em seguida apresentaremos um resumo da hipótese de Lathrap, Brochado e Noelli (Brochado, 1984; Brochado, 1989; Noelli, 1996), baseada em evidências linguísticas e arqueológicas. Uma terceira hipótese, apresentada de forma preliminar em Mello e Kneip (2005), será detalhada aqui e substanciada com dados linguísticos. Recentemente, mais dois trabalhos foram publicados: Eriksen e Galucio (2014), que trata especificamente com a expansão do tronco Tupi, que não é foco deste trabalho, mas que futuramente poderão esclarecer de melhor forma as migrações dos povos Tupi (não Tupi-Guarani), e Michael, ChousouPolydouri, Bartolomei, Donnelly, Wauters, Meira, e O'Hagan (2015), que dá mais detalhes sobre subgrupos maiores de línguas Tupi-Guarani, reunindo as vezes dois ou mais dos subgrupos de Rodrigues (1985). Estes nós 
mais antigos da subdivisão Tupi-Guarani foram propostos parcialmente em Mello (2000), porém foram bem melhor detalhados neste trabalho recente. Futuramente, ele poderá esclarecer as migrações internas dentro da Amazônia, principalmente a área oriental e central.

Pelo lado arqueológico, novas evidências sustentam a localização da origem Tupi-Guarani nos médios e baixos cursos dos rios Xingu e Tocantins, áreas de interflúvio e no entorno desses rios, corroborando o presente estudo (Almeida e Neves, 2015).

\section{Origem e dispersão dos povos Tupi-Guarani: as visões linguística e arqueológica}

\subsection{A visão linguística (Mapa 1)}

Urban $(1992,1996)$ trata da dispersão dos povos do tronco Tupi segundo a ‘Teoria da Migração Linguística' e pela distribuição das línguas isoladas. Das dez ramificações do tronco Tupi, a maior dispersão é a da família linguística Tupi-Guarani, que vai da atual Argentina à Guiana Francesa, da costa do Brasil à Amazônia Peruana. Das outras nove ramificações, seis têm representantes na região das cabeceiras dos rios Madeira, Mamoré e Guaporé, onde hoje está o estado de Rondônia. Urban ainda tenta fortalecer sua hipótese considerando a concentração de línguas isoladas da região e supondo as regiões com tais concentrações de diversidade linguística como aquelas de povoamento mais antigo e, portanto, como possíveis focos de dispersão de grandes famílias linguísticas. Mostra também que há uma grande concentração de línguas isoladas onde hoje é o estado de Rondônia e na Amazônia boliviana, e considera esta como a possível região de origem dos grupos Tupi. Urban não trata especificamente dos sentidos de dispersão Tupi-Guarani dentro do tronco Tupi, mas considera a região de partida como entre o Madeira e o Xingu, e provavelmente bastante recente (Urban, 1992). Portanto, as principais rotas dos grupos Tupi-Guarani estão de acordo com as de Rodrigues, tendo os grupos Guarani e Tupinambá seguido o sentido sul, descendo as bacias do Paraguai e Prata, e depois para o leste, atingindo o litoral, com os Tupinambá subindo a costa no sentido norte. Os grupos Tupi-Guarani amazônicos teriam seguido o sentido leste a partir do centro de dispersão até atingir o meio-norte. 
Mapa 1. Origem e Dispersão.

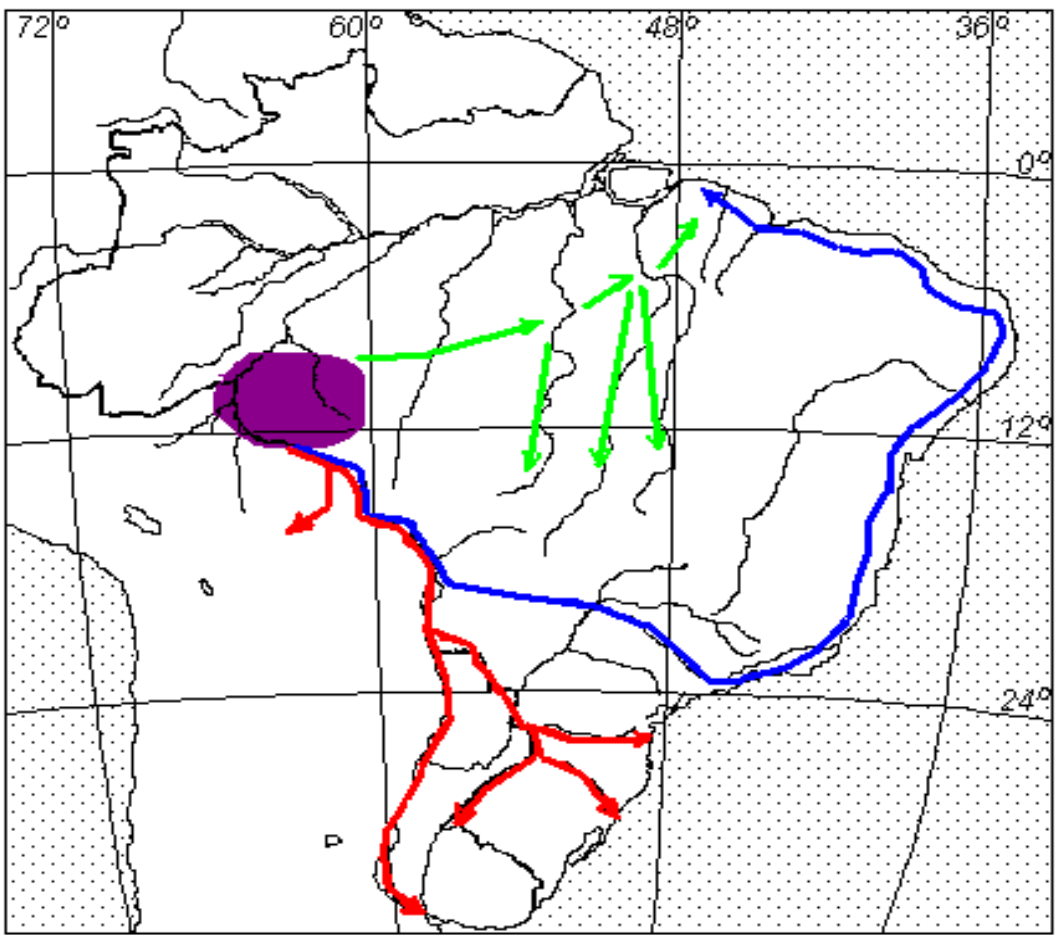

Tupi-Guarani, aproximadamente, segundo Urban (1992) e Rodrigues (2000). A origem está marcada em roxo. A rota de migração Tupinambá está em azul e a Guarani em vermelho. Em verde estão as rotas de migração de outros grupos da família Tupi-Guarani.

Urban baseia-se em parte nas idéias de Rodrigues, mas introduz também como evidência a concentração de línguas isoladas. Rodrigues (2000) explicita melhor quais seriam as rotas principais da diáspora Tupi-Guarani, de acordo com a classificação interna da família. Para a proposta de origem, novamente a evidência mais forte é baseada na 'Teoria da Migração Linguística', e considera as cabeceiras do rio Madeira como a região de maior diversidade linguística do tronco Tupi. Para as rotas de migração dos povos Tupi-Guarani, é considerada a mesma região de origem dos povos Tupi. Considera que haveria duas levas distintas de povos proto-guarani e proto-tupinambá sentido sul. A primeira teria se dividido, tendo um ramo penetrado na Bolívia e outro seguido para o sul até a bacia Paraná/Uruguai e alguns grupos seguido rios em sentido leste (rio Paranapanema e rio Uruguai), chegando 
ao litoral. Os Tupinambá teriam descido também o rio Paraguai, mas rumariam para leste um pouco mais ao norte do que os Guarani, tendo seguido os rios Grande e Tietê chegando ao litoral onde hoje é São Paulo, e depois ocupado a costa no sentido sul-norte. Os povos TupiGuarani que não saíram da Amazônia teriam migrado sentido leste, mas não por grandes rios e sim seus afluentes, que muitas vezes quase se emendam. Assim, houve diferentes subdivisões que correspondem às diferenciações fonológicas dos subconjuntos de Rodrigues (1985a), referentes às bacias do Madeira (subconjunto VI), Tocantins (subconjunto IV) e Xingu (subconjuntos V e VII).

\subsection{A visão arqueológica (Mapa 2)}

Brochado (1984), logo no início de sua tese, chama a atenção para o fato de que a arqueologia do leste da América do Sul deveria ser vista como a pré-história dos grupos indígenas que os europeus encontraram quando aqui chegaram, no século XVI e subsequentes. Esta relação entre o registro arqueológico e o registro etnográfico, embora em geral possa ser problemática, encontraria no caso brasileiro condições favoráveis, em virtude da continuidade cultural observada entre as comunidades indígenas existentes quando da chegada do invasor europeu e aquela encontrada no registro arqueológico (Prous, 1992).

Uma cronologia, em arqueologia, é estabelecida utilizando métodos de datação diretos e indiretos. Os métodos diretos fazem uso de propriedades físicas e químicas dos materiais escavados para determinar a idade absoluta da peça ou estrutura. Exemplos são os métodos do Carbono 14 e da Termoluminescência, entre outros. Os métodos indiretos procuram estabelecer relações de ordem temporal, sem determinação de idade. Por exemplo, a estratigrafia: as camadas inferiores são mais antigas que as superiores.

Os arqueólogos consideram que determinadas características da cultura material permanecem no tempo, e que as variações encontradas nestas características dentro de um mesmo sítio, ou entre diferentes sítios de uma região, são frutos da passagem do tempo. Desta forma, analisando a sequência de variações destes aspectos da cultura material, combinada com a determinação de cronologias para as camadas e sítios onde foram encontrados, é possível estabelecer uma sequência cronológica de ocupação da região. 
Um elemento bastante utilizado para estabelecer esta cronologia é a cerâmica. Aspectos como as características de forma, da pasta, do antiplástico, da queima, da decoração etc., são determinados e são analisados sua variação no tempo e no espaço. Assim, a característica decorativa pintura policrômica, comum tanto aos Tupinambá quanto aos Guarani, e observada na região amazônica com o nome de "Tradição Polícroma Amazônica (TPA)", em sítios considerados anteriores a dispersão TupiGuarani, coloca nesta região a origem destes grupos (Brochado, 1984).

Na ampla área da América do Sul ocupada pelos povos Tupi-Guarani, a cerâmica apresenta variações regionais. Assim, na área que corresponde ao território ocupado pelos Tupinambá, no período histórico, a decoração cerâmica é predominantemente pintada, com vasos abertos de boca quadrangular ou oval, base quase plana e bordas reforçadas. $\mathrm{Na}$ área ocupada pelos Guarani, a cerâmica apresenta vasos mais bojudos, com decoração corrugada ou pintada, fundo arredondado ou cônico (Prous, 1992).

Em resumo, o modelo de Brochado e Lathrap (Brochado, 1984) coloca o centro de origem da família Tupi-Guarani na região de confluência do rio Madeira com o Amazonas. A partir deste local, uma cisão no proto-povo Tupi-Guarani teria resultado, grosso modo, em duas rotas de expansão: do povo que teria dado origem aos Tupinambá, indo para leste até encontrar o oceano, pela boca do Amazonas, e então descendo pela costa até o litoral de São Paulo; e um outro grupo, que daria origem aos Guarani, inicialmente subindo o rio Madeira para o interior da Amazônia, e então, no sentido de norte para o sul, até chegar ao rio da Prata e litoral sul do Brasil.

Com o tempo, este modelo foi sendo aperfeiçoado. Brochado (1989, p.72-73), considerando a profundidade temporal associada ao troco Tupi (em torno de 5000 anos), relaciona a Subtradição Guarita (com decoração pintada em vasos abertos, com inciso de linhas largas), parte da TPA, com os povos proto-Tupi. Um série de movimentos no interior da Amazônia, causados por aumento da pressão demográfica, resultaram na separação das diferentes famílias linguísticas e na diferenciação de suas características cerâmicas. Aqueles que dariam origem aos proto-Tupi-Guarani (a cerca de 2500 anos), estavam na região entre a foz do rio Madeira e a desembocadura do Iça-Putumayo.

Um ramo, com cerâmica da subtradição Guarita, teria subido o rio Madeira rumo sul, dando início à expansão proto-Guarani. Um contato 
com as tradições cerâmicas do leste da Bolívia resultaria nas características da cerâmica Guarani. A data sugerida para o início deste movimento é em torno de 200 a.C. Um outro ramo, portando cerâmica da subtradição Miracanguera, teria dado origem aos proto-Tupinambá. Este ramo desceria a costa atlântica, posteriormente penetrando no interior seguindo os rios costeiros, mantendo as formas cerâmicas com bocas ovaladas e quadrangulares, mas perdendo as formas fechadas e antropomórficas, e simplificando a decoração. Seu início é proposto em torno do ano zero da era cristã.

Mapa 2. Origem e Dispersão Tupi-Guarani segundo Noelli (1996). O centro da cerâmica Tupi está marcado em lilás. A área hachurada com lilás possui antecedentes relacionados à cerâmica Tupi. Em azul está a área com informações arqueológicas e históricas dos Tupinambá fora da Amazônia, e em vermelho a dos Guarani.

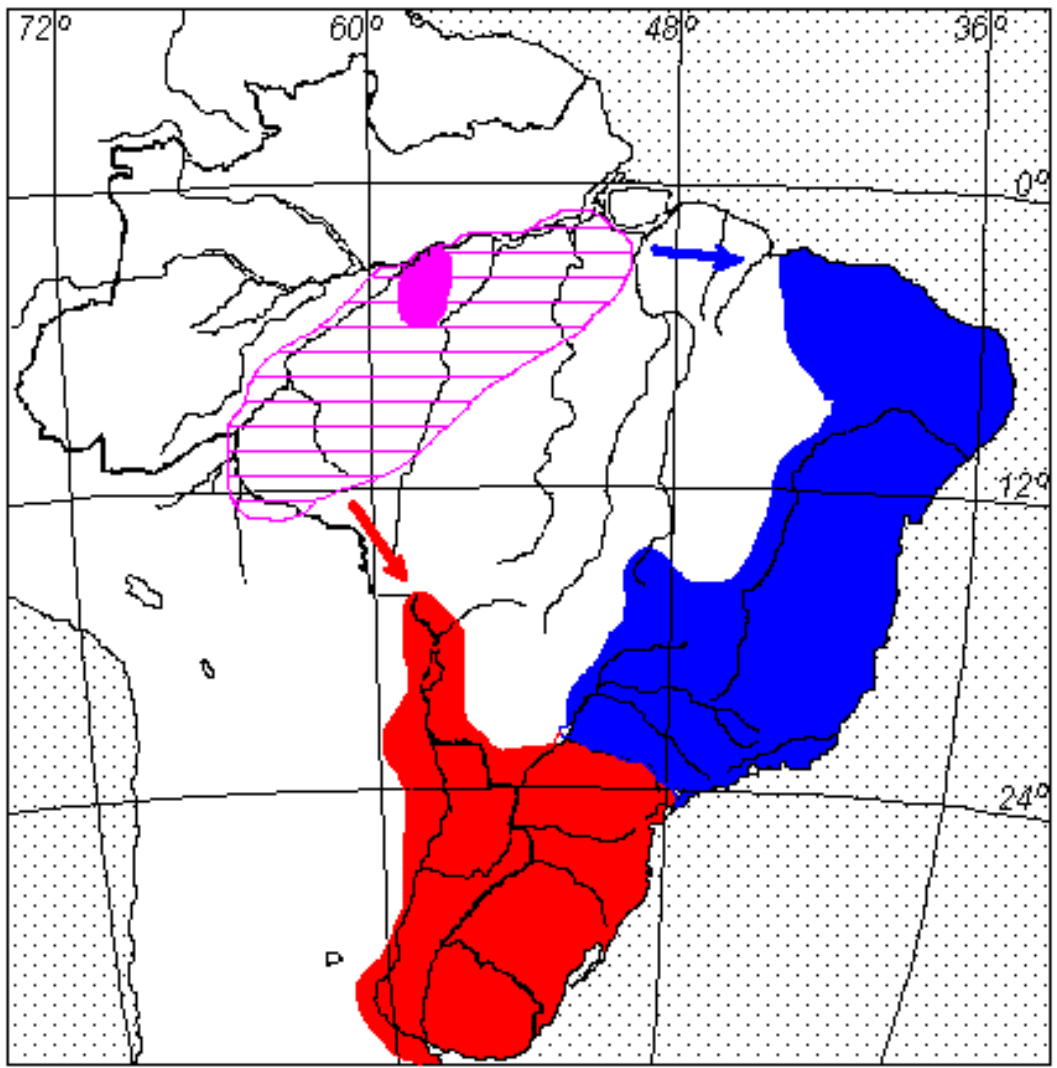

Noelli (1996) sintetizando e explicitando o modelo proposto por Lathrap e Brochado, situa a origem proto-Tupi na margem direita do 
Amazonas, na foz do Madeira. A expansão Guarani se deu rumo sul, subindo o Madeira, sofrendo influência de grupos da Bolívia, e ocupando toda da área correspondente ao sul brasileiro, Mato Grosso, Mato Grosso do Sul, Uruguai, partes da Argentina, da Bolívia e do Paraguai. Já os Tupinambá teriam se expandido a partir do baixo Amazonas, alcançado o litoral em sua foz, ocupado todo o litoral de norte para o sul, penetrando no interior pelos rios que desaguam no Atlântico, até alcançarem o Trópico de Capricórnio. É importante ressaltar que este modelo faz uso também das evidências linguísticas já citadas. A cronologia proposta pelo autor é um pouco mais antiga que a derivada da glotocronologia.

Alguns autores enxergam problemas sérios nos fundamentos que justificam a hipótese arqueológica aqui apresentada. Os problemas vão desde a cronologia das tradições cerâmicas e a associação entre tradição cerâmica e falantes de proto-língua, passando pela ausência de datas comprovadoras em sítios que estariam na área correspondente à proto-Tupi-Guarani (Viveiros de Castro, 1996; Urban, 1996; Heckenberger, Neves e Petersen, 1998).

Heckenberger et al. (1998) criticam a associação entre TPA e povos proto-Tupi, com base em análise do material recolhido de sítios próximos à desembocadura do rio Negro, que estariam em plena área de origem proto-Tupi. A argumentação aponta que a cerâmica encontrada nestes sítios não está entre a mais antiga de toda a Amazônia, o que contraria a hipótese de origem dos Tupi na Amazônia central. Quanto à origem dos Tupi-Guarani, os autores não descartam um relacionamento entre as cerâmicas das subtradições Guarita e Miracanguera com uma expansão posterior à dos Tupi.

\section{Uma segunda visão linguística que favorece parcial- mente a hipótese de Brochado (1989)}

As aplicações anteriores da 'Teoria da Migração Linguística' consideram apenas a diversidade linguística dentro do tronco Tupi, já que é bastante clara a concentração desta diversidade onde hoje é o estado de Rondônia. A partir desta evidência tão forte, subtende-se o foco de dispersão Tupi-Guarani (família) na mesma região, sem ser considerado que em Rondônia há apenas um subconjunto Tupi-Guarani com línguas bastante semelhantes: Parintintin, Juma, Tenharin, Urueuwauwau e Amundava. Se formos considerar a região de maior diversidade linguística da famí- 
lia Tupi-Guarani, esta seria mais próxima ao leste amazônico, onde está concentrado o maior número de línguas: Asurini do Trocará, Parakanã, Tembé, Tapirapé, Guajajara, Guajá, Urubu-Kaapór, Aurê e Aurá, Anambé, Wayampé, Emerillon, Asurini do Xingu, Araweté e Kamayurá (14 línguas), de quatro subconjuntos diferentes segundo a classificação de Rodrigues (1985a), e cinco subgrupos segundo AUTOR. Podemos aumentar para seis o número de subconjuntos presentes nesta região se considerarmos a antiga ocupação Tupinambá na costa do Maranhão e o sentido da dispersão como norte-sul, concordando em parte com a hipótese de Brochado (Mapa 3).

Mapa 3. Origem e dispersão Tupi-Guarani segundo este artigo. A área roxa mostra o centro de origem do tronco Tupi. A seta amarela mostra o deslocamento dos falantes do proto-tupi que deram origem à família Tupi-Guarani. A área verde-escuro representa o centro de origem da família Tupi-Guarani. A seta verde-claro mostra a volta de um ramo da família Tupi-Guarani para a área proto-Tupi. A expansão Tupinambá, em azul, parte da área proto-Tupi-Guarani. A Guarani, em vermelho, retorna à área que coincide com a de origem proto-Tupi, antes de migrar rumo sul.

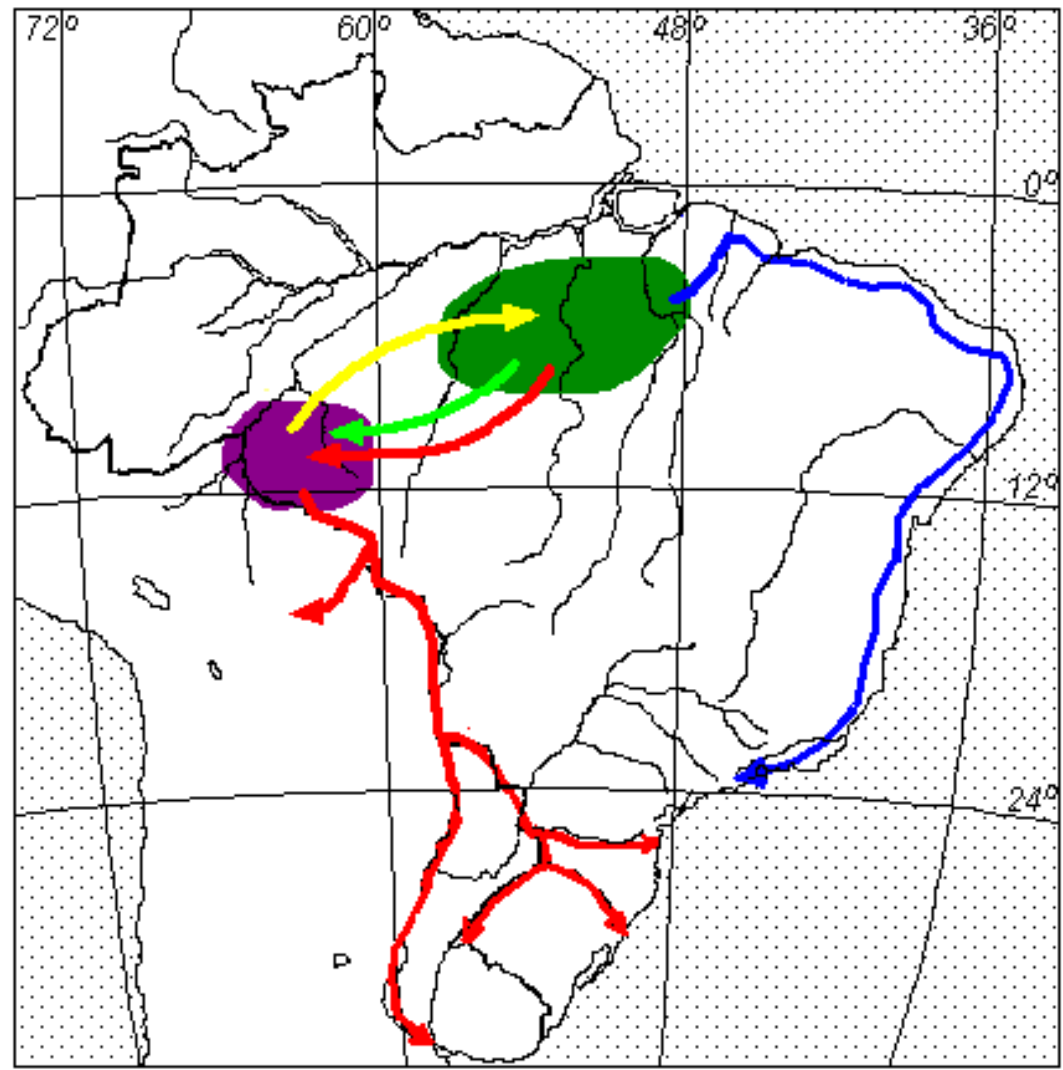




\subsection{Evidências a favor da hipótese linguística que coloca o foco da dispersão Tupi-Guarani no leste amazônico}

a) Aplicação da 'Teoria da Migração Linguística' (Campbell, 1999) à família Tupi-Guarani (TG). A diversidade linguística aponta para um foco de dispersão no leste amazônico. A proximidade de grupos proto-tupi-guarani próximos ao litoral favorece a idéia de que a dispersão Tupinambá deve ter se dado no sentido norte-sul. Haveria desta forma povoações tupinambá não muito afastadas umas das outras, formando um contínuo com os grupos tupi-guarani localizados no leste amazônico e meio-norte. Sabemos que no início do povoamento europeu na América do Sul, os Tupinambá ocupavam cerca de 3/4 do litoral que hoje corresponde ao Brasil, do Maranhão até São Paulo, e que as diferenças linguísticas entre o norte e o sul eram mínimas, o que sugere uma rápida dispersão. Dados linguísticos coletado pelo padre jesuíta José de Anchieta e dados dos padres capuchinhos no Maranhão do século XVII demonstram esta unidade linguística.

b) Contato de povos Tupi-Guarani com povos Karíb. Seja qual for a região de origem dos Karíb, no maciço das Guianas, ou no Brasil central (hipótese do viajante alemão Karl von den Steinen) (Urban, 1992), o eixo de migração Karíb que penetra no Brasil estaria na direção norte-sul, das Guianas até o estado de Mato Grosso, não passando pela área proto-Tupi proposta por Urban e Rodrigues. Se houve um contato Tupi-Guarani-Karíb, como evidenciado em Rodrigues (1985b), este teria que ter acontecido no leste ou no meio-leste amazônico, por onde teriam transitado grupos Karíb.

c) A migração pelo rio Paraguai, entrando na bacia do rio da Prata seria exclusiva dos Guarani e das línguas Tupi-Guarani da Bolívia. Há assim uma certa continuidade da área Guarani na região central da América do Sul (Bolívia e estados do Mato Grosso e Mato Grosso do Sul) em direção aos estados do sul do Brasil, chegando ao litoral. Se os Tupinambá tivessem seguido rota de migração semelhante (pelo menos na parte que desce o Paraguai e Paraná), seria mais esperado que houvesse vestígios no caminho. No entanto, sabemos que a interiorização de uma língua derivada do Tupi (Tupi de São Vicente, parente próximo do Tupinambá), a Língua Geral Paulista, se deu em tempos históricos, principalmente com os bandeirantes (Rodrigues, 1994). 
d) Diferenciações lexicais Guarani-Tupinambá. Estudo de subagrupamento interno realizado por AUTOR demonstra que há feixes de isoglossas que isolam as línguas do subgrupo Guarani (muitas vezes conjuntamente às línguas TG bolivianas) versus isoglossas que englobam os grupos TG amazônicos e o Tupinambá. Exemplos: para 'abóbora' o Tupinambá e várias línguas amazônicas apresentam cognatos da proto-forma do proto Tupi-Guarani *jurumu. Houve uma diferenciação lexical nas línguas Guarani, que têm cognatos de 'anai'. O mesmo traçado de isoglossas se dá para os itens lexicais 'morcego' (Tupinambá e línguas amazônicas: cognatos de anyrá, com o y representando a vogal central alta não arredondada, enquanto as línguas guarani têm cognatos de mopy); 'anta' (Tupinambá e línguas amazônicas *tapi?ir , o ? representando a oclusiva glotal, enquanto as línguas Guarani têm *morevi); e 'guariba' (Tupinambá e outras *wariB, B representando a fricativa bilabial sonora, e línguas Guarani *karaja).

\section{Discussão}

Por esta proposta alguns subconjuntos de línguas Tupi-Guarani teriam voltado à área de dispersão dos proto-Tupi. Colocar a área de dispersão Tupi-Guarani em região diferente da de origem dos proto-Tupi pressupõe um movimento de fluxo e refluxo de alguns grupos Tupi. Teria acontecido um movimento Tupi-Guarani para o leste amazônico e depois um movimento de volta das línguas que atualmente se encontram em Rondônia (Parintintin, etc), e também da divisão que originou os proto-Guarani, que devem ter descido o rio Paraguai, chegando à bacia do Prata. Este mesmo argumento pode ser favorável a nossa proposta, já que existem divisões do tronco Tupi nesta área de fluxo e refluxo cujas línguas são muito mais próximas às línguas Tupi-Guarani (como Sateré-Mawé e Aweti) do que as ramificações das línguas Tupi de Rondônia (famílias Mondé e Ramarama, por exemplo).

Almeida (2008), trabalhando em uma região do médio Tocantins, obteve uma data que poderia estar relacionada com o início do processo de cisão da família Tupi-Guarani (Sítio Bela Vista, 480+-20 a.C.) a partir do tronco Tupi. O autor, no entanto, desconfia desta data devido às poucas informações obtidas do sítio e de sítios próximos na região. 
De qualquer forma, esta revisão da origem e rotas de dispersão dos futuros Guarani e Tupinambá aproxima os modelos linguístico e arqueológico. É de se esperar que uma pesquisa mais abrangente nas regiões canditadas a origem dos Tupi e dos Tupi-Guarani ajude a esclarecer esta questão.

\section{Conclusão}

Pretendemos aqui trazer à tona a discussão sobre origem e dispersão dos povos Tupi-Guarani e o que há de discordância e concordância com a comparação de hipóteses provenientes de análises de dados linguísticos e aqueles provenientes de análise de dados arqueológicos. Até a proposta apresentada neste artigo, havia uma nítida discordância entre a hipótese linguística (Rodrigues, 1985a; Rodrigues, 2000; Urban, 1992, 1996) de um lado, e a arqueológica (Brochado, 1984; 1989; Noelli, 1996), de outro. Propomos aqui uma nova hipótese linguística também de acordo com a 'Teoria da Migração Linguística', focalizando a diversidade dentro da família Tupi-Guarani, e não dentro do tronco Tupi, que foi o ponto de partida para as outras propostas. Se deslocarmos a região de origem dos proto-Tupi-Guarani para o leste amazônico, é muito mais plausível que os Tupinambá tenham atingido a costa e se dispersado pelo litoral a partir do norte.

\section{Bibliografia}

Almeida, F. O. (2008). O Complexo Tupi da Amazônia Oriental. Dissertação (mestrado), Universidade de São Paulo: São Paulo, SP.

Almeida, F. O., Neves, E. G. (2015). Evidências arqueológicas para a origem dos tupi-guarani no leste da amazônia, MANA 21(3), 499-525.

Brochado, J. P. (1984). An ecological model of the spread of pottery and agriculture into Eastern South America. Tese (doutorado), University of Illinois at Urbana-Champaign: Urbana-Champaign.

__. (1989). A expansão dos Tupi e da cerâmica da tradição policrômica amazônica. Dédalo, 27, 65-82.

Campbell, L. (1998). Historical linguistics. Edinburgh University Press: Edimburgo. 
Crowley, T. (1997). Historical linguistics: an introduction. Oxford University Press: Auckland.

Eriksen, L. \& Galucio, A. V. (2014). The Tupian Expansion. In: P. Muysken \& L. O'Connor (eds.), The Native Languages of South America: Origins, Development, Typology (pp. 177-202). Cambridge: Cambridge University Press.

Heckenberger, M. J., Neves, E. G. \& Petersen, J. B. (1998). De onde surgem os modelos? As origens e expansões Tupi na Amazônia Central. Revista de Antropologia, 41.1, 69-96.

Michael, L., Chousou-Polydouri, N., Bartolomei, K., Donnelly, E., Wauters, V., Meira, S. \& O'Hagan, Z. (2015). A bayesian phylogenetic classification of Tupí-Guaraní. LIAMES, 15(2), 193-221.

Mello, A. A. S. \& Kneip, A. (2005). Diálogo arqueologia - linguística: origem e dispersão Tupi-Guarani. Atas do XIII Congresso da $S A B$, em $C D$. Universidade Federal do Mato Grosso do Sul, Campo Grande, MS.

Noelli, F. S. (1996). As hipótese sobre o centro de origem e rotas de expansão dos Tupi. Revista de Antropologia, 39.2, 7-53.

Prous, A. (1992). Arqueologia brasileira. Brasília: Editora Universidade de Brasília.

Rodrigues, A. D. (1985a). Relações internas na família língüística TupiGuarani. Revista de Antropologia, 27/28, 33-53.

Evidence for Tupi-Carib relationships. (1985b). In: H. E. M. Klein e L. R. Stark (orgs.), South American Indian Languages: Retrospect and Prospect (pp. 371-404). University of Texas Press: Austin.

_. (1994). Línguas brasileiras: para o conhecimento das línguas indígenas. Edições Loyola: São Paulo.

(2000). Hipótese sobre as migrações dos três subconjuntos meridionais da família Tupi-Guarani. II Congresso Nacional da ABRALIN e XIV Instituto Linguístico (pp. 1596-1605). Associação Brasileira de Linguística: Florianópolis.

Urban, G. (1992). A história da cultura brasileira segundo as línguas nativas. In: M. C. Cunha (org.), História dos índios no Brasil (pp. 87102). FAPESP/ Cia das Letras/ Secretaria Municipal de Cultura: São Paulo. 
_. (1996). On the geographical origins and dispersion of Tupian languages. Revista de Antropologia, 39.2, 61-104.

Viveiros de Castro, E. (1996). Comentário ao artigo de Francisco Noelli. Revista de Antropologia, 39.2, 55-60. 